\title{
Guidance for Processing FRESH JUICES in Retail Operations
}




\section{Credits}

The guidance for processing in retail operations has been prepared through support from the USDA Cooperative State Research, Education and Extension Service project no. 2001-11420 funded through the University of Florida in cooperation with Florida A\&M University and the Association of Food and Drug Officials (AFDO) during October 2001 through January 2004. Development of these respective guides was conducted by assigned voluntary Subcommittees combining academic, regulatory and industry expertise and a formal Steering Committee. The committee participants can be viewed in the Listing of Committee Members. The same information can be viewed at www.AFDO.org with additional visual aids and links to other website support and references.Design by Julissa Hernandez. Printed by IFAS Communication Services.

\section{Project Investigators}

Victor Garrido, University of Florida

Ray Mobley, Florida A\&M University

Steve Otwell, University of Florida

Keith Schneider, University of Florida

\section{Fresh Juice Subcommittee}

Rene Goodrich, Univ. FL Steven Grover, NRA

Linda Harris, UC Davis

Don Kautter, FDA/CFSAN

Dan King, FCPA

Steve Pao, VA State Univ.

*Lead coordinator

\section{Project Steering Committee}

Jim Austin, AFDO

Shirley Bohm, FDA

Alfred Bugenhagen, NY Dept. Agric. \& Markets

Joe Corby, NY Dept. Agric. \& Markets

Carl Custer, USDA FSIS OPH B

Faye Felstein, FDA

Dan Sowards, TX Dept. of Health

Victor Garrido, University of Florida

Steven Grover, National Restaurant Assoc.

Janis McCabe, Publix Supermarkets, Inc.

Ray Mobley, Florida A\&M University
Gale Prince, Kroger

Keith Schneider *

Tim Weigner, FMI

Debra Williams, FL DACS

Gerald Wojtala, MI Dept. Agric.

Betsy Woodward, AFDO
Steve Otwell, University of Florida

Paul Panico, $\mathrm{OH}$ Dept. of Agriculture

Gale Prince, The Kroger Co.

Fred Reimers, HEB Grocery Co.

Denise Rooney, AFDO

Doug Saunders, VA Dept. of Agriculture

Keith Schneider, University of Florida

Jenny Scott, Natl. Food Processors Assn.

Timothy Weigner, Food Marketing Institute

Gerald Wojtala, MI Dept. of Agriculture

Betsy Woodward, AFDO 


\section{Background}

This guidance has been prepared in response to a notable increase in on-site retail processing (manufacturing) of foods traditionally processed in controlled plant environments. Such retail processing can involve, but is not limited to acidifying, smoking, drying, fermenting, curing, reduced oxygen packaging, and other operations that are traditionally done at a food manufacturing plant level. The key distinction for processing as related to this guidance is that the processing occurs on-site in the retail setting.

This guidance is intended for retailers and regulatory personnel to help understand the controls to implement in a retail operation in order to process and sell safe food products. It can be referenced in developing considerations for variances for any exception or special provision to state or local food safety or sanitary codes. It addresses those special variances required by the FDA Food Code which may require HACCP plans for those jurisdictions that have adopted those portions of the FDA Food Code. In addition, it also applies to regulatory oversight and/or approval for regulatory overlap that may occur between the states' processing requirements and the state or local retail food safety and sanitary codes. This guidance assumes retail compliance with applicable retail food codes, prerequisite standard sanitary operations procedures, and labeling requirements specified in $21 \mathrm{CFR} 101$. This guidance is not intended to replace or duplicate existing regulations, but it does offer a reference for more uniform practices.

\section{Disclaimer}

This guidance is not a binding set of requirements. The information provided in the guidance are recommendations based on current science, commercial experience and practical considerations as assembled by the assigned committees and reviewed by a variety of selected experts and the Project Steering Committee. Use of these recommendations would likely result in retail processing practices that are acceptable to the pertinent authorities for food safety. Retail compliance and enforcement will remain within the interpretations and decisions of the pertinent state and local regulatory authorities. 


\section{Product Description}

Juice is defined in 21 CFR 120.1; "juice"' refers both to beverages that are composed exclusively of an aqueous liquid or liquids extracted from one or more fruits or vegetables and to the juice ingredient in those beverages that contain other ingredients in addition to juice. In this guidance, the term "juice product" refers both to beverages that contain only juice and to the juice ingredient of beverages that are composed of juice and other ingredients. Fresh juice is defined as a juice product that has not been subjected to a process, such as pasteurization, to prevent, reduce or eliminate microbiological hazards.

\section{Related terminology:}

Approved source - a source that has been determined to conform to principles, practices, and standards that protect public health.

Fresh, Untreated Juice Products - a juice product that has not been processed to prevent, reduce, or eliminate hazards.

Food Hazard - any biological, chemical, or physical agent that is reasonably likely to cause illness or injury in the absence of its control.

Identifiable source - can include the name and address of the immediate supplier and the actual source or location of the supplies.

Pasteurization - the process or treatment (usually heat) applied to reduce the most resistant microorganism of public health significance to a level not likely to present a public health risk in the food.

Retail and Foodservice Establishments - the Food Code definition includes establishments in which juice is produced and sold directly to consumers in stores, from roadside stands, at farmers' markets, and in food service operations (such as juice bars and restaurants). 
Flow Diagram of Operations

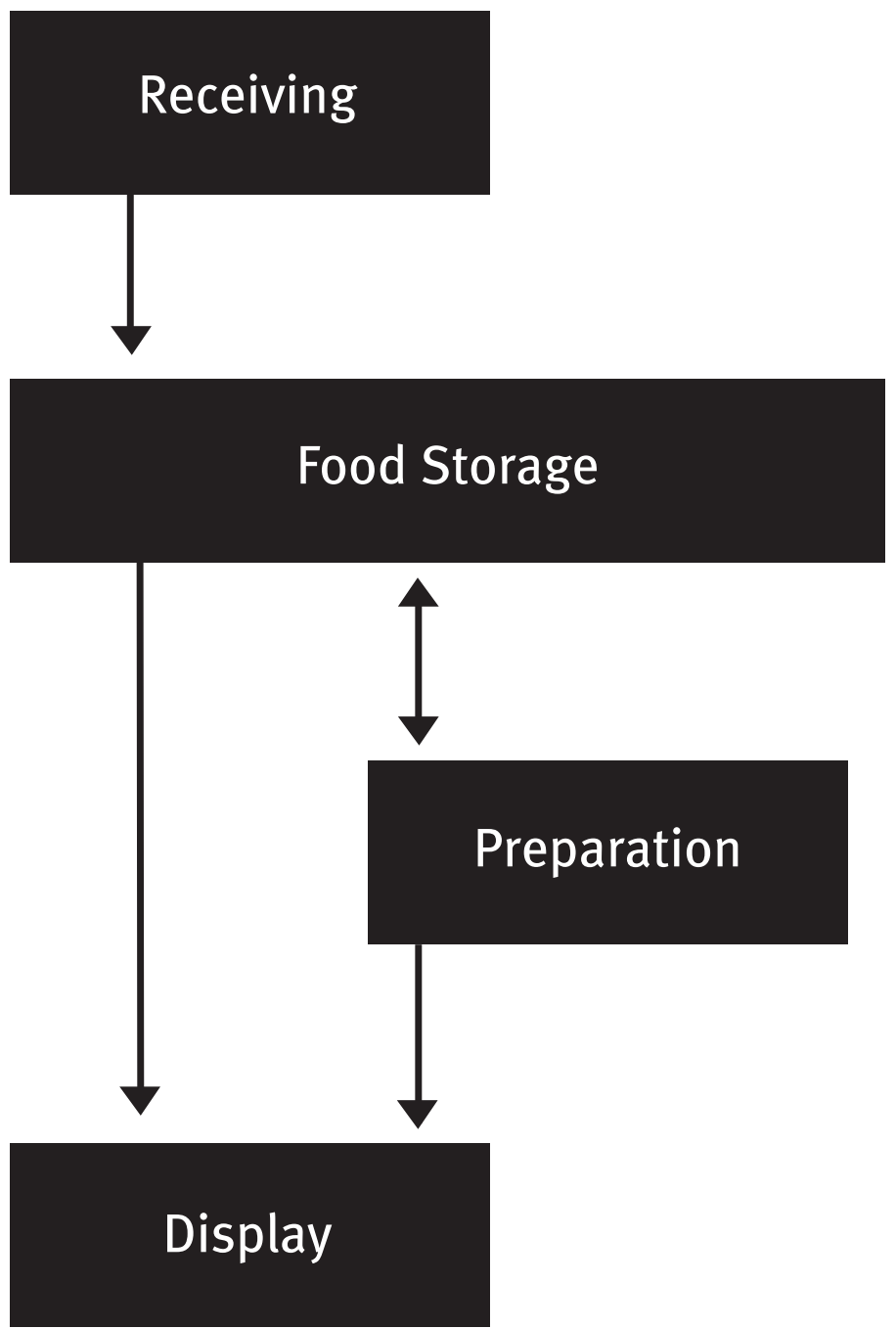




\section{Check List for Operations}

\section{Receiving}

All products, including fruits, vegetables and other juice components (e.g., health food supplements, wheat germ, etc.) are obtained from identifiable, approved sources. If juice components are provided from a source outside the fresh juice operations, this source must be approved, identifiable and/or be able to provide processing records that document proper GMP, GAP and/or HACCP programs as recommended in these guidelines for fresh juice operations. The information and prior agreements of suppliers with the fresh juice operation provide controls to prevent potential problems due to safety concerns associated with these products (Appendix 1 - Food Safety Hazards). The use of signed grower/supplier agreements can assure the retail processor that the fruits or vegetables used to make juice products are produced and harvested in a safe and acceptable manner.

Traceability of raw fruits and vegetables may be important if pathogen contamination or illness occurs (i.e., harvest location, primary processor) and may be required by the buyer.

All potentially hazardous food components are to be delivered at appropriate temperatures. Each processor must be aware of the specific requirements for the types of product they will be receiving. If proper conditions are absent or questionable, a calibrated thermometer is available to monitor the internal temperature of the incoming foods before acceptance (Appendix 2 - Calibrations).

Retail establishment actively manages a program for routine inspection of incoming products for approved sources, product condition and temperature as necessary, integrity of packaging and proper label information, and documents product acceptance or rejection with dates, times and the person in decision, plus any necessary comments.

All employees, including workers involved in loading and unloading of food products before and after transport, should adhere to strict personal hygiene practices.

\section{Food Storage}

Storage can include temperature control units used to hold perishable foods. The foods can include raw ingredients and/or finished juice products. These types of foods can be stored in separate units or segregated with protection in the same unit. Display counters are not considered storage units and should not be used to store raw ingredients.

Foodborne pathogens may be introduced or allowed to grow and multiply in food items during storage or while in transit. Produce should be protected from potential contamination by microorganisms, insects, chemicals, rodents, waste products, toxic material, unclean equipment, unnecessary handling, or other agents of public health significance at all times. The following guidelines for storage and transporting of produce intended for juice products should be observed:

Maintain storage area in clean and sanitary manner. Bottles, caps and packaging materials should be stored in a clean, dry, pest free area.

Insure that storage areas are free of insects and rodents and constructed to prevent the entrance and harborage of insects and rodents.

Refrigeration unit(s) is operating to assure the potentially hazardous food can be maintained at the appropriate temperature for the particular product. 
Routine monitoring for proper refrigerated storage unit temperatures involves use of a continuous timetemperature recording device or periodic checks with a thermometer. All temperature recorders and thermometers are calibrated periodically or as needed (see Appendix 3: Calibrations). When storage conditions allow for product internal temperature above $41^{\circ} \mathrm{F}\left(5^{\circ} \mathrm{C}\right.$ ) (or other pre-determined temperature limit) are detected, an evaluation is conducted of all potentially hazardous food stored in the unit. The evaluations will document the actual temperature of the products and duration of exposure. Corrective action is taken and documented. All suspect product is discarded.

The storage unit(s) is clean and orderly:

Products are contained and/or covered for protection.

Products are marked for identity and duration in storage (dated), as appropriate.

Packaged products, ready-for-display, are segregated from products that require further handling or processing.

Products are not being stacked without adequate support and prevention of any leakage between products.

Drippage due to condensation, cooler pan leaks or other wet sources is prevented into or on packaged products.

Products are stored above the floor (approx. 6 inches) and away from walls and the ceiling.

The schedule for product rotation should use a 'First-in First-out' (FIFO) rule.

\section{Preparation}

The work area, facilities and utensils should be designated and/or dedicated to the fresh juice operations. If it is necessary to share work space and facilities, segregate from other processing activities, have a defined schedule of operations, and clean and sanitize work area between operations to prevent potential cross contamination of the fresh juice products.

Standard Operating Procedures for basic sanitation and food safety are used and documented daily (Appendix 4 - Daily SOP Check List).

A production should be kept to aid in product traceability (Appendix 5 -Production Log).

\section{Preparation - Processing and Handling of Fresh Juice}

As with the production of any food product, current Good Manufacturing Practices (cGMPs) (21 CFR 110) and/or Good Retail Practices (GRPs) (FDA Food Code) should be part of any sanitation program. The following recommendations should be preformed daily, monitored and logged. Employees should initial the daily work log provided. 
Only wholesome fresh fruit and vegetables (produce) should be used for juice extraction. At minimum, produce should be cleaned and processed in a manner consistent with commercial packinghouse processes. This cleaning process has either taken place on these premises, or at a commercial packinghouse from which the produce was procured. Recent research demonstrated using high $\mathrm{pH}$ sanitizers and waxes can help achieve significant reductions in surface microbial contamination. Grading can also provide significant reduction in natural microflora in juice. Produce is sorted (inspected) to effectively eliminate all rots or defective produce with cuts, splits, punctures, or other defects that may allow microbial contamination immediately prior to processing. Use of dropped fruit or windfalls is not recommended for processing fresh juice.

Produce previously handled by consumers should not be used for production of fresh squeezed juice without an effective washing/sanitizing step before juice extraction. Bare hand contact should be minimized to protect produce from contamination during sorting/inspection and to preclude contamination of the raw juice products.

Cleaned, brushed and/or sanitized produce, as appropriate, should be maintained in a clean, secure, sanitary and enclosed environment until extraction. If a sanitary and enclosed area is not available, or if produce is sourced directly from the field, the produce should be treated to reduce microbial contaminants.

Employees handling produce should maintain proper personal hygiene.

Extractor and other food contact equipment have been properly cleaned and sanitized per manufacturer's guidelines and operate in a sanitary enclosed work area. Food-contact surfaces of extraction equipment are impervious and cleanable, in good repair, and cleaned and sanitized at a regular frequency. Couplings, fittings, and other parts associated with extractors, pumps, and other equipment are disassembled for cleaning.

Containers used for packaging must be food grade and maintained in clean condition. If fresh juice is packaged, it must be treated under a HACCP plan to achieve a 5 log reduction in pathogens or be labeled with a warning statement (Appendix 3 - Product Labels)

Juice has been properly refrigerated at $41^{\circ} \mathrm{F}\left(5^{\circ} \mathrm{C}\right)$ or below following extraction.

The preparation schedule is arranged to minimize exposure of potentially hazardous foods to ambient room temperature conditions.

\section{Display}

Display involves holding the finished products in temperature control units for a specified duration and condition for public sale. The preparation of fresh juice is for immediate consumption by consumers, and does not have the shelf-life of the pasteurized product. Retail preparation and display introduces more prolonged storage that must be controlled and monitored to assure product safety before consumption.

The display unit maintains the fresh juice products at or below $41^{\circ} \mathrm{F}$.

Product packaging is properly labeled and includes instructions for proper storage and shelf-life (Appendix 3 - Product Labels).

Product is rotated to assure FIFO movement of product. Product is discarded once shelf-life has been met and is not re-labeled.

Product is lot and/or date coded to better track product date and to facilitate recall issues. 


\section{Appendices}

\section{Food Safety Hazards}

2. Calibrations

3. Product Labels

4. Daily SOP Check List

5. Production Log 


\title{
Appendix 1
}

Fresh juice product, like all other unprocessed foods, may occasionally become contaminated with human pathogens or chemical contaminants which may cause illnesses. Contamination may occur in the field, during postharvest handling or during transportation. Juice foodborne illnesses have been associated mostly with microbes that are associated with and spread via fecal contamination or by exposure to contaminated water. While outbreaks associated with fresh juice have been rare, several incidents have occurred recently. The primary implicated product(s) of concern (PIPC) for each hazard have been listed below. This is not intended to be a complete list of implicated products nor a statement regarding risk, but rather a historical reference of some of the outbreaks that have occurred.

\section{Biological}

\author{
Hazard: E. coli 0157:H7
}

Problem: Can be found on incoming produce. If not eliminated prior to the preparation step or its growth prevented through proper holding temperatures, in those products that support growth, could cause illness.

PIPC: Apple Cider

Controls: Use produce from identifiable sources; wash with potable water and/or approved food grade sanitizer.

\section{Hazard: Salmonella spp.}

Problem: Can be found on incoming produce. If not eliminated prior to the preparation step or its growth prevented through proper holding temperatures, in those products that support growth, could cause illness.

PIPC: Orange Juice

Controls: Use produce from identifiable sources; wash with potable water and/or approved food grade sanitizer.

\section{Hazard: Clostridium botulinum}

Problem: Rare occurrence, but has been found in homemade carrot juice.

PIPC: Carrot Juice (homemade)

Controls: Maintain strict temperature control of $41^{\circ} \mathrm{F}\left(5^{\circ} \mathrm{C}\right)$ or below to control growth.

\section{Hazard: Cryptosporidium parvum}

Problem: Can be found on contaminated produce or in contaminated water and could infect consumers.

PIPC: Apple juice

Controls: Purchase agreements with producers that confirm adherence to GAP principles and guidelines. Produce should be cleaned, sanitized and sorted. Potable water should be used for cleaning, washing and/or sanitizing components. 


\section{Chemical}

Hazard: Patulin

Problem: Mycotoxin present when moldy apples are used in processing.

PIPC: Apple juice

Controls: Avoid use of visibly moldy or damaged product, cull all suspect fruit. Use supplier agreements to ensure quality of incoming raw material. 


\section{Temperature Monitoring Devices - Thermometers}

Many types of thermometers and temperature recording devices are readily available for use in food handling operations. We recommend thermistors, thermocouples and infrared thermometers with either a digital or analog readout. All of these instruments are acceptable for use in the food processing operations as long as the operator understands how they are used and if they are calibrated for proper readings.

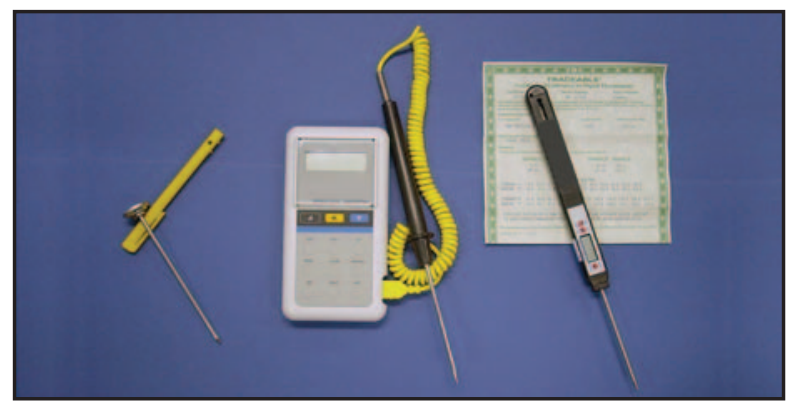

The method and frequency of calibration for thermometers will depend on the use and temperature range where the equipment is used. In the absence of manufacture's recommendations, thermometers should be calibrated at least once a month with more frequent calibrations when the instrument is physically abused or if the readings are questionable.

\section{Temperature Monitoring Devices (TMD) - Calibration Procedures (options):}

a. TMD's can be calibrated against a thermometer certified by the National Institute of Standards and Technology (NIST) by simply comparing both units at two preset temperatures (hot and cold).

b. TMD's can be calibrated using an ice-water slush. Insert the temperature probe into a mixture of ice and water slush and stir (2-3 $\mathrm{min})$ until the thermometer stabilizes. The probe should be at the center of the container. The thermometer should read $32 \pm 1^{\circ} \mathrm{F}\left(0 \pm 1^{\circ} \mathrm{C}\right)$. Adjust accordingly or discard and replace the faulty thermometer.

c. Hot point calibration is used when monitoring temperatures higher than room temperature (e.g., cooking temperatures). Heating blocks or boiling water can be used for this calibration. When using the boiling water procedure, the probe is placed inside a container with boiling water until the thermometer stabilizes (2-3 min). The probe should be at the center of the container. The thermometer should read $212 \pm 1^{\circ} \mathrm{F}\left(100 \pm 1^{\circ} \mathrm{C}\right)$ or appropriate temperature according to elevation (Table 1 - Altitude to Boiling Point of Pure Water Relationship). Adjust accordingly or discard and replace the faulty thermometer.

d. A combination of the procedures $b$ and $c$ is recommended for a more accurate calibration of thermometers used to moniter a wide range of temperatures.
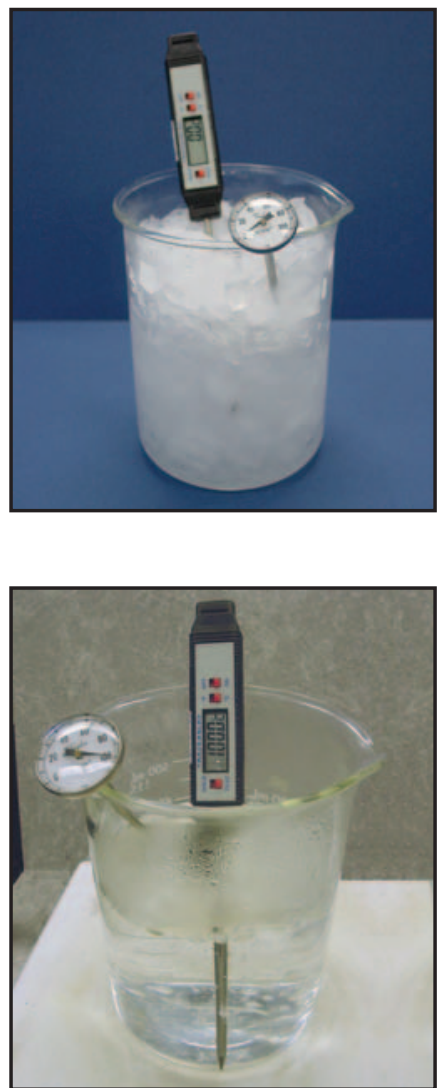


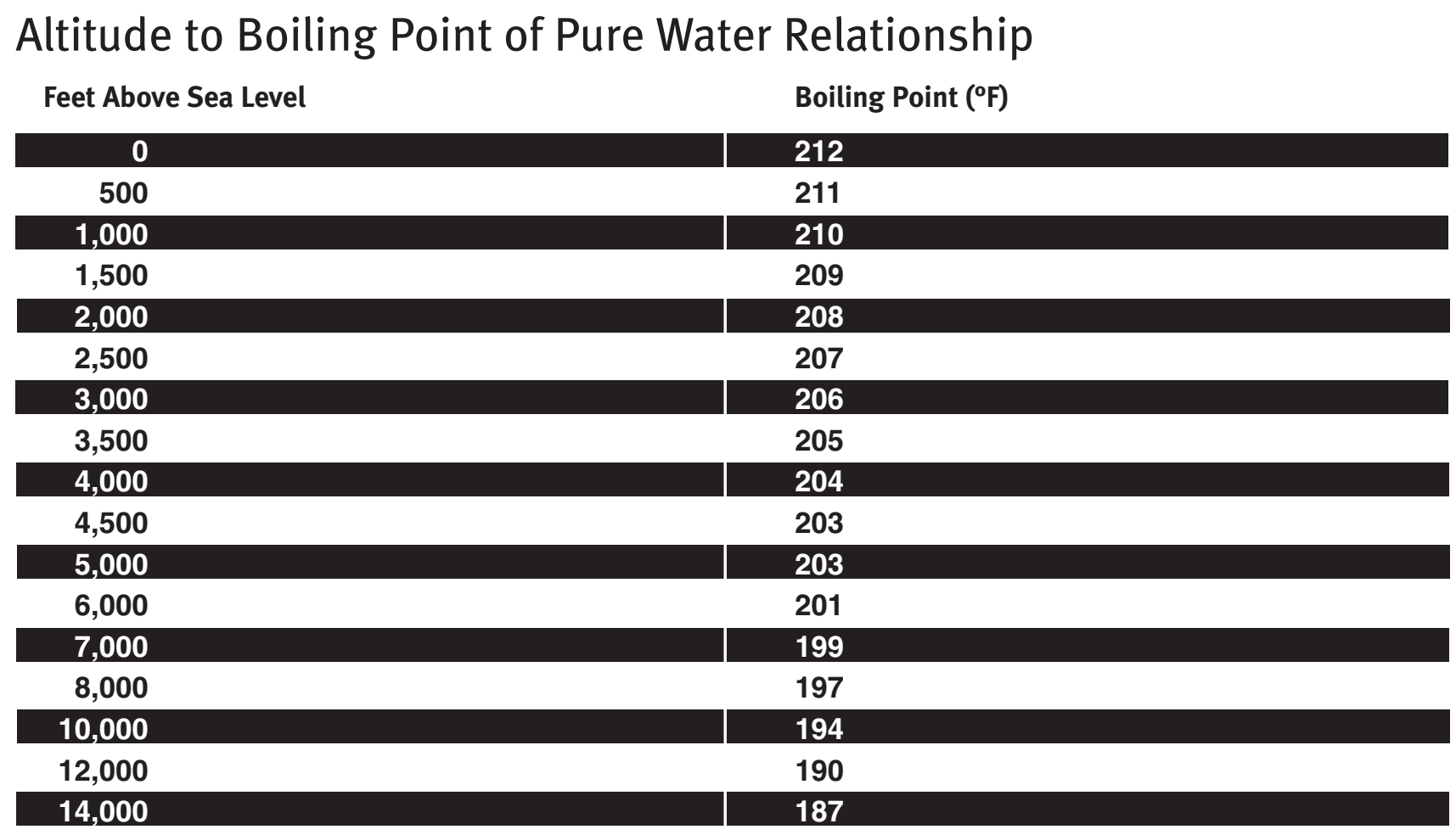

Source: Thermometer Calibration, food safety webpage, University of Nebraska Cooperative Extension (http://foodsafety.unl.edu/html/thermometer.html) 


\section{Appendix 3}

\section{Product Labels}

All juice products sold through display in a retail setting must be in compliance with applicable state food code requirements and contain label information pursuant to the requirements of 21 CFR 101. No nutritional label is required as long as the seller does not make a claim in regards to the juice product (e.g., contains fiber). If the juice product is fresh, unprocessed, the Food Code, Section 3-404.11 states that the juice packaged in a Food Establishment shall be:

Treated under a HACCP plan as specified in 8-201.2(B)-(E) to attain a 5-log reduction, which is equal to a $99.999 \%$ reduction, of the most resistant microorganisms of public health significance; or

If not treated to yield a 5-log reduction of the most resistant microorganisms of public health significance;

Labeled as specified under 3-602,11, and

Labeled as specified in 21 CFR 101.17(g) with the phrase:

\section{WARNING: This product has not been pasteurized and, therefore, may contain harmful bacteria which can cause serious illness in children, the elderly, and persons with weakened immune systems.}

The juice processor can avoid labeling their product with the warning statement if they chose to follow these requirements: juice processed in a manner that will produce, at a minimum, a 5-log (i.e., 100,000 fold) reduction in the pertinent microorganism for a period at least as long as the shelf-life of the product when stored under normal and moderate abuse conditions. For the purposes of this regulation, the "pertinent microorganism" is the most resistant microorganism of public health significance that is likely to occur in the juice (Appendix 1 - Food Safety Hazards). 


\section{Label Information}

1. Product type used to describe the product. The description should be in common terms associated with the product and recognized by the consumer.

2. Product ingredients listed in order of the amount in the food.

3. Net weight and pricing information.

4. Bar code for product inventory and identity.

5. Lot and/or date code the product.

6. Perishable food statement to instruct consumer handling and storage.

7. Company name and address, including zip code.

8. Production code or other identification to facilitate tracking and recall.

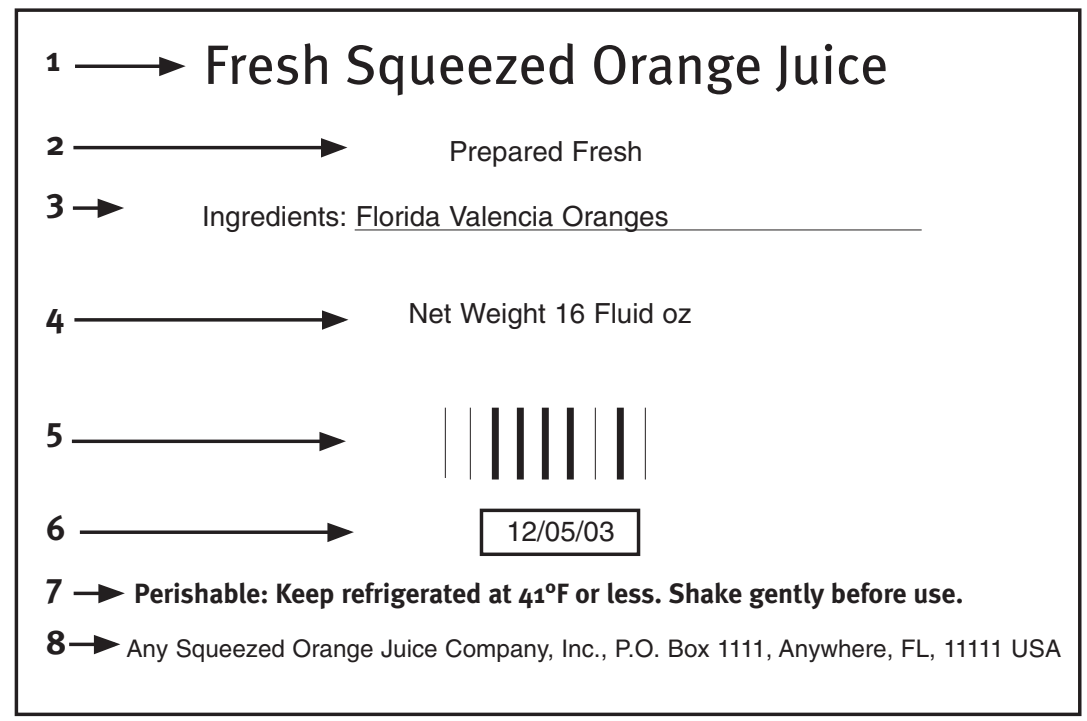

Disclaimer: This label is simply provided as a guide. Retailers should consult with their local authorities to assure compliance with more immediate requirements in their region. 
Store Name/Number:

DATE:

\begin{tabular}{|c|c|c|c|c|}
\hline Storage & Time/Temp & Time/Temp & Time/Temp & Time/Temp \\
\hline Refrigerators $\left({ }^{\circ} \mathrm{F} /\right.$ Time $)$ & ${ }^{\circ} \mathrm{F}$ & ${ }^{\circ} \mathrm{F}$ & ${ }^{\circ} \mathrm{F}$ & ${ }^{\circ} \mathrm{F}$ \\
\hline Freezers $\left({ }^{\circ} \mathrm{F} /\right.$ Time $)$ & ${ }^{\circ} \mathrm{F}$ & ${ }^{\circ} \mathrm{F}$ & ${ }^{\circ} \mathrm{F}$ & ${ }^{\circ} \mathrm{F}$ \\
\hline Display & Time/Temp & Time/Temp & Time/Temp & Time/Temp \\
\hline
\end{tabular}

\begin{tabular}{l|l|l|l|l}
\hline Display temperature $\left({ }^{\circ} \mathrm{F} /\right.$ Time) & ${ }^{\circ} \mathrm{F}$ & ${ }^{\circ} \mathrm{F}$ & ${ }^{\circ} \mathrm{F}$ & ${ }^{\circ} \mathrm{F}$ \\
\hline $\begin{array}{l}\text { Clean and Orderly. Food in good condition } \\
\text { and properly labeled. }\end{array}$ & & & & \\
\hline
\end{tabular}

SOP CHECK LIST

\section{Work Area}

Orderly; Clean and Sanitized tables, countertops and sinks. Orderly, all work surfaces cleared. Clean floor and drains

Proper storage and labeling of chemicals and cleaning items

Wet and dry trash separate and removed from work area.

All utensils, pots, pans, bowls, cutting boards, cooking or heating equipment properly cleaned and sanitized.

Thermometer and recorder available and calibrated

\section{Personnel}

Personnel Health, hand-washing practices, glove use, clean and well maintained outer garments, proper hair covering and no jewelry.

\section{Food Storage}

All food protected, dated and labeled properly

Refrigerators and freezers clean, orderly and operating correctly.

\section{Comments}

\begin{tabular}{l|l|l|l|l}
\hline \multicolumn{1}{c|}{ Pre-0p Time } & \multicolumn{1}{c}{ Post-0p } \\
\hline Employee Initials & & & & \\
\hline Manager Review & & & & \\
\hline
\end{tabular}

This particular form is not mandated but it does indicate information that should be recorded to demonstrate an appropriate process for food safety. Different and additional forms can be used to record the same information. 
Appendix 5

Production Log

\begin{tabular}{|c|c|c|c|c|}
\hline Product Description & Prep Time & Pull Date & Lot Code \# & Operator \\
\hline Apple-orange & $05 / 09$ 4:00pm & $8 / 05 / 03$ & 001-007 & KRS \\
\hline & & & & \\
\hline & & & & \\
\hline & & & & \\
\hline & & & & \\
\hline & & & & \\
\hline & & & & \\
\hline & & & & \\
\hline & & & & \\
\hline & & & & \\
\hline & & & & \\
\hline & & & & \\
\hline & & & & \\
\hline & & & & \\
\hline & & & & \\
\hline & & & & \\
\hline & & & & \\
\hline & & & & \\
\hline & & & & \\
\hline & & & & \\
\hline & & & & \\
\hline & & & & \\
\hline & & & & \\
\hline & & & & \\
\hline & & & & \\
\hline & & & & \\
\hline & & & & \\
\hline & & & & \\
\hline & & & & \\
\hline & & & & \\
\hline & & & & \\
\hline & & & & \\
\hline & & & & \\
\hline & & & & \\
\hline & & & & \\
\hline & & & & \\
\hline & & & & \\
\hline & & & & \\
\hline & & & & \\
\hline
\end{tabular}




\section{Notes:}


1. This document is FSHN05-06, one of a series of the Food Science and Human Nutrition Department, Florida Cooperative Extension Service, IFAS, University of Florida, Gainesville, FL 32611. Published: February 2005. Please visit the EDIS Web site at http://edis.ifas.ufl.edu

2. Keith R. Schneider, PhD, assistant professor, University of Florida, Food Science and Human Nutrition Department, University of Florida, Gainesville, FL 32611; Victor Garrido, research coordinator and W. Steve Otwell, PhD, professor, Food Science and Human Nutrition Department, Aquatic Food Product Lab, University of Florida, Gainesville, FL 32611; and Ray Mobley, PhD, Florida A\&M University.

The Institute of Food and Agricultural Sciences is an equal opportunity/affirmative action employer authorized to provide research, educational information and other services only to individuals and institutions that function without regard to race, color, sex, age, handicap, or national origin. For information on obtaining other extension publications, contact your county Cooperative Extension Service office. Florida Cooperative Extension Service / Institute of Food and Agricultural Sciences / University of Florida / Larry R. Arrington, Dean 
